\title{
Time Trends of Noncommunicable Diseases Mortality in Basra province During 2010-2019
}

\author{
Sadiq A. Rahmah ${ }^{1}$, Shrouk Abdulrazak Hassan Alibraheem², Rajaa A. Mahmoud ${ }^{3}$ \\ \{altyye149@gmail.com ${ }^{1,}$ shrouk.albraheem@stu.edu.iq ${ }^{2}$,rahmedmahmoud@gmail.com ${ }^{3}$ \} \\ Department Community Health Techniques, College of Health \& Medical Tech/Basrah, South Technical \\ University, $\operatorname{Iraq}^{1}$ \\ Southern Technical University/College of Health \& Medical Technology, Basra/Iraq² \\ University of Basra/ Al Zahraa College of Medicine, Basra/Iraq ${ }^{3}$
}

\begin{abstract}
Chronic Noncommunicable diseases are a primary cause of illness and deaths worldwide, that responsible for 41 million deaths out of 57 million each year that represent $71 \%$ of all causes of death worldwide. To estimate the cause-specific death rate due to noncommunicable diseases in Basra province during the period 2010-2019. This study is a descriptive, retrospective study including all deaths due to noncommunicable diseases recorded in Official Statistical records in Basra health Directorate during the period 20102019. The time trend of death due to non-communicable diseases is increasing due to the rise of cause-specific death rate from 238 per 100000 in 2010 to 240 per 100000 in 2019. The highest death rate of non-communicable diseases is a cardiovascular disease that has a death rate equal to 213 per 100000 in 2010 to 227 per 100000 in 2019 compared with other selected non-communicable diseases in this study found the cardiovascular diseases first cause of death in non-communicable found to be in this study
\end{abstract}

Keywords: Chronic Diseases, Noncommunicable Diseases, Deaths of Basra Province.

\section{Introduction}

Chronic Noncommunicable diseases are a leading source of mortality and morbidity worldwide, that responsible for 41 million deaths each year that represent $71 \%$ of all causes of death worldwide ${ }^{[1]}$ The burden of NCDs has been rise as a concern globally, has long been a source of concern in developed countries; however, they are causing increasing concern in developing countries due to their demographic and epidemiological transition, the impact of globalization on consumption habits, and the aging of populations. It has been identified as one of the biggest challenges to the health of the 21 st century ${ }^{[2]}$. The reasons for this increased by $20.5 \%$ from 2009 to 2019, which represented 7.1 million deaths in 2019 compared to $2009^{[3]}$ There are four leading causes of NCD deaths, that including the first one Cardiovascular disorders with reach to 17.9 million deaths annually, fallowing be the second cancers that kill more than nine million, while the mortality from respiratory diseases that reached to 3.9 million, for diabetes annual death equal to1.6 million, NCD deaths accounting for more than $80 \%$ of all premature death ${ }^{[4]}$. Additionally, approximately 15 million people aged 30-69 die prematurely because of NCDs Surprisingly, developing countries, which account for half of all premature NCD deaths, have more problems than developed countries. Furthermore, within countries, poor people are more likely to suffer from NCDs. ${ }^{[5]}$ chronic noncommunicable diseases have been a 
major public health concern in Iraq, as they are responsible for most deaths, responsible for more than $55 \%$ of all mortality and $30 \%$ were premature death in $2016^{[6]}$. Despite the limited information regarding the true prevalence of non-communicable diseases in Iraq the main impediments include prevention and regulation treatment and diagnostic materials as well as the lack of cooperation between the public and private sectors, other challenges were the limited institutional and human resources ${ }^{[7]}$. In Iraq, $\mathrm{NCD}_{\mathrm{s}}$ are estimated to account for $55 \%$ of all deaths where $(27 \%$ cardiovascular diseases, $11 \%$ Cancers, $4 \%$ Diabetes, $2 \%$ chronic respiratory diseases) while $11 \%$ for Other NCDs compared with $17 \%$ Communicable, maternal, perinatal, and nutritional conditions and $28 \%$ Injuries ${ }^{[8]}$. the Objectives of this study was to estimate the cause-specific death rate due to noncommunicable diseases in Basra province during the period 2010-2019.

\section{Materials and Methods}

This study is a descriptive retrospective study including all patients fulfilling due to noncommunicable diseases that were recorded in Official Statistical records in Basra health Directorate during the period 2010-2019. The sample size includes 52008 patients who died from the most prevalent non-communicable diseases (cardiovascular diseases, cancer, diabetes, hypertension, asthma, and Epilepsy). Data was collected from the Basra health directorate depending on the death certificate and forensic medicine reports for the above diseases. Furthermore, data were analysed by using Visual Foix Bro 7 and Microsoft Excel 2016 to the estimation of the cause of death rate from data shown in Table 1.

Table 1. Distribution of NCDs mortality in total population during the period between 2010-2019.

\begin{tabular}{|c|c|c|c|}
\hline $\mathbf{N}$ & Years & Total population & Non-communicable deaths \\
\hline 1 & $\mathbf{2 0 1 0}$ & 2467531 & 4455 \\
\hline 2 & $\mathbf{2 0 1 1}$ & 2788470 & 4799 \\
\hline 3 & $\mathbf{2 0 1 2}$ & 2591153 & 4803 \\
\hline 4 & $\mathbf{2 0 1 3}$ & 2672425 & 4878 \\
\hline 5 & $\mathbf{2 0 1 4}$ & 2744758 & 5323 \\
\hline 6 & $\mathbf{2 0 1 5}$ & 2818803 & 5517 \\
\hline 7 & $\mathbf{2 0 1 6}$ & 2894594 & 5820 \\
\hline 8 & $\mathbf{2 0 1 7}$ & 2972166 & 5776 \\
\hline 9 & $\mathbf{2 0 1 8}$ & 2908491 & 5992 \\
\hline 10 & $\mathbf{2 0 1 9}$ & 2985073 & \\
\hline
\end{tabular}

The following equation calculating the Cause-Specific Death Rate due to non-communicable diseases ${ }^{[9]}$.

CSDRs $=\underline{\text { number of death due to a specific cause in a specific period }} \times \mathbf{1 0 0 0 0 0}$

Total population in the midpoint of a period 


\section{Results}

Time trends of deaths due to non-communicable diseases during 2010-2019. Regarding the Cause-Specific Deaths Rate of non-communicable diseases. the results show an increase in the death rate of NCDs during 2010-2019.for each year death rate decrease from 328.2 per 100000 in 2010 to 323.2 per 100000 in 2014 that represent the lowest death rate after that increase to 356 per 100000 in 2017 that represent as highest death rate and gradual dropping to 340.2 per 100000 in 2019 as shown in Fig.1

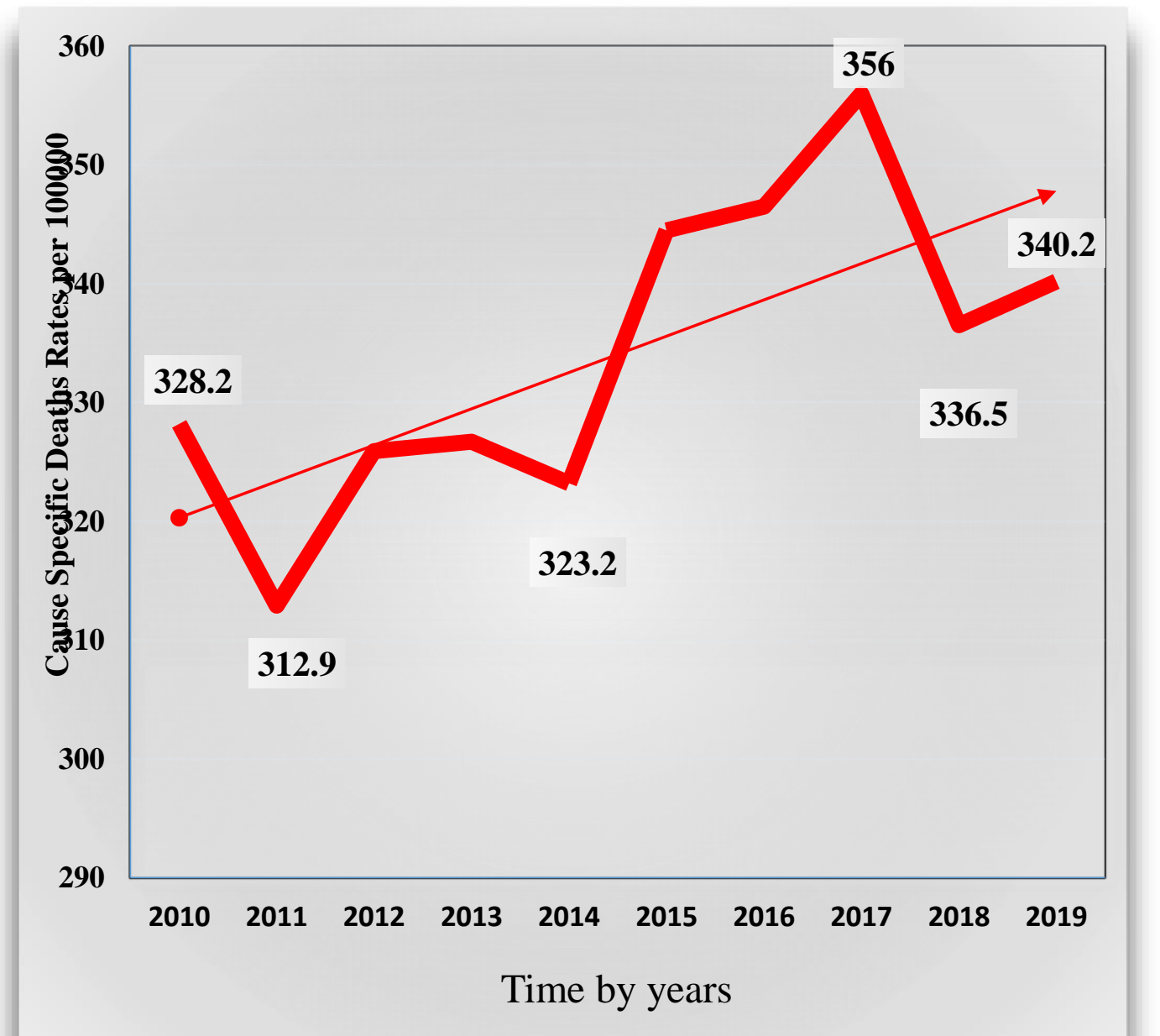

Fig 1. Time trend of death due to NCDs (overall) during 2010-2019. 
Concerning to most preventable non-communicable diseases, the study found the cardiovascular diseases first cause of death in non-communicable diseases with the death rate from 213.2 per 100000in 2010 to 227 per 100000 in 2019 followed by cancer as the second cause of death with a death rate of 64.9 per 100000 in 2010 to 66.6 per 100000 in 2019 compared to those of others (diabetes mellitus, hypertension, asthma, and Epilepsy) during the period 2010-2019 as available in Fig.2

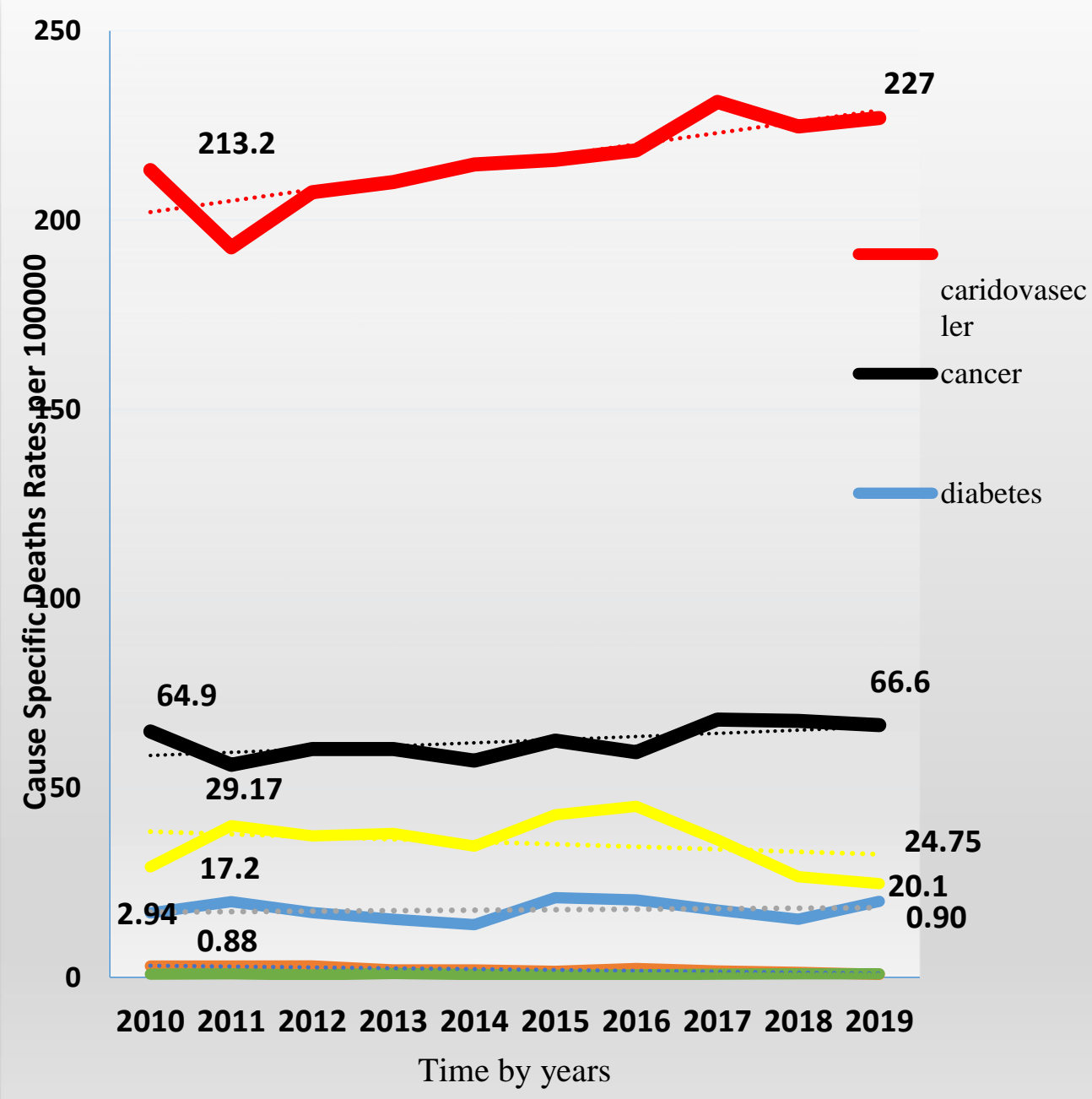

Fig 2. Time trend of death due to NCDs (Separately)during 2010-2019. 


\section{Discussion}

This study is conducted to assess time trends of death due to Noncommunicable diseases in Basra during 2010-2019. The results show an increase in mortality due to noncommunicable diseases in the last ten years. The Eastern Mediterranean area, which ranks worst in the area in terms of mortality from NCDs, is confronted with a slew of health issues stemming from violent wars and political upheavals. ${ }^{[10]}$ However, this is descriptive research, not an evaluation of specific governmental policies, actions, or changing national circumstances. The interpretation of these trends in NCD-related premature avertable mortality should be done with extreme care. It is critical, for example, to determine the relative contributions of NCD incidence and survival rates. Competition from fatalities from non-NCD causes, particularly those at early ages, will impact mortality attributed to premature avertable mortality from NCDs, which is especially concerning in conflict contexts. There may also be temporal gaps between the decrease of amenable mortality and the implementation of remedies and policies. ${ }^{[5]}$ Cause of. Death Information System is a critical component of the monitoring and evaluation of health interventions to prevent and reduce non-communicable diseases and related risk factors ${ }^{[11]}$ can expanse this increase due to Mortality of noncommunicable diseases in Basra according to cause of death registration has increased in the past decade using several data sources to collect information about the cause of death. In the context of the comprehensive ICD-10 coding system, the quality of cause of death is also improving, and a priority of public health policy is to improve the diagnosis of the cause of death by providing death certificates from adult coroners $^{[12]}$ Combined with the WHO report, interventions that focus on multiple risk factors, such as eating a balanced diet, regular physical exercise, and avoiding tobacco products, can prevent at least $80 \%$ of premature heart disease, stroke, and diabetes. $2,40 \%$ of malignancies. ${ }^{[13]}$ In future investigations of NCD-related premature avertable mortality, a more detailed study of these consequences is required. the WHO global recommendation to reduce premature deaths from major non-communicable diseases with a goal of $25 \times 25$ (reduce $25 \%$ of the premature death by 2025) still some developing countries such as Iraq do not achieve this goal by increasing the death rate over time, it may be due to the increased level of risk factors for noncommunicable diseases, as most people are not aware of the impact of non-communicable diseases and association with their risk factors and the weak healthcare system in this country ${ }^{[14]}$.

\section{Conclusion}

Noncommunicable diseases remain a major and persistent problem in Basra due to the high mortality rate during the past ten years, and this confirmed that Basra is still far from the global target of the World Health Organization to reduce deaths due to non-communicable diseases by $25 \times 2025$.

\section{References}

[1] World Health Organization. "WHO package of essential noncommunicable (PEN) disease interventions for primary health care." (2020).

[2] Global Health Policy. The U.S. Government and Global Non-Communicable Disease. Availableathttps://files.kff.org/attachment/fact-sheet-The-US-Government-and-Global-NonCommunicable-Disease-Efforts (accessed 30 April 2021) Published: Jan 29, 2019

[3] Qiao J, Lin X, Wu Y, Huang X, Pan X, Xu J, Wu J, Shan PF, Ren Y. Global Burden of Non- 
Communicable Diseases Attributable to Dietary Risks in 1990-2019.

[4] Bigna JJ, Noubiap JJ. The rising burden of non-communicable diseases in sub-Saharan Africa. The Lancet Global Health. 2019 Oct 1;7(10):e1295-6.

[5] Kazemi E, Khosravi A, Aghamohamadi S, Shariati M, Kazemeini H. Trends in premature mortality in the Islamic Republic of Iran: probability of dying between ages 30 and 70 years. Eastern Mediterranean Health Journal. 2021;27(1):33-40.

[6] Pengpid S, Peltzer K. Overweight and obesity among adults in Iraq: prevalence and correlates from a National Survey in 2015. International Journal of Environmental Research and Public Health. 2021 Jan;18(8):4198.

[7] Naser RN, Al-Ghuzi AA. PREVALENCE OF NON-COMMUNICABLE DISEASES AMONG GERIATRIC POPULATION IN AL-NASIRIYAH CITY 2015. University of Thi-Qar Journal Of Medicine. 2016;11(1):1-23.

[8] World Health Organization. Noncommunicable diseases country profiles 2018.

[9] Friis, R. and Sellers, T. 'Measures of Morbidity and Mortality Used in Epidemiology', Epidemiology for

PublicHealthPractice,p.50.Availableat:http://samples.jbpub.com/9781284103717/9781449651589_C H03 _Friis.pdf (2013)

[10] World Health Organization. Monitoring Health in the Sustainable Development Goals: 2017 update.

[11] Peykari N, Hashemi H, Dinarvand R, Haji-Aghajani M, Malekzadeh R, Sadrolsadat A, Sayyari AA, Asadi-Lari M, Delavari A, Farzadfar F, Haghdoost A. National action plan for non-communicable diseases prevention and control in Iran; a response to emerging epidemic. Journal of Diabetes \& Metabolic Disorders. 2017 Dec;16(1):1-7.

[12] World Health Organization. The impact of chronic disease in the islamic republic of Iran. Genouva: Organization. 2002.

[13] Eyre H, Kahn R, Robertson RM, ACS/ADA/AHA Collaborative Writing Committee, ACS/ADA/AHA Collaborative Writing Committee Members, Clark NG, Doyle C, Hong Y, Gansler T, Glynn T, Smith RA. Preventing cancer, cardiovascular disease, and diabetes: a common agenda for the American Cancer Society, the American Diabetes Association, and the American Heart Association. Circulation. 2004 Jun 29;109(25):3244-55.

[14] World Health Organization. Global NCD target: reduce premature deaths from NCDs. World Health Organization; 2016. 